\title{
Effect of Ethanolic Extract Fractions of Boerhaavia diffusa in Doxorubicin-induced Myocardial Toxicity in Albino Rats
}

\author{
Shrishail Kashinath Nimbal, Basavaraj Chanabasappa Koti* \\ Department of Pharmacology, KLE University's College of Pharmacy, Vidyanagar, Hubballi, Karnataka, INDIA.
}

\begin{abstract}
Background: Doxorubicin is a Anthracycline derivative and has proven efficacy in various malignancies. It is the most effective cytotoxic agent in current use. The clinical usefulness is limited due to its cardiac toxicity. Objectives: To study the preventive role of ethanolic extract fractions of Boerhaavia diffusa (BD) against doxorubicin (Dox) induced myocardial toxicity in albino rats. Methods: The ethanolic extract of whole plant of Boerhaavia diffusa was prepared by hot extraction method and further fractionated into Petroleum ether (PEBD), Chloroform (CLBD), Ethyl acetate $(E A B D)$ and Aqueous (AQBD) fractions by increasing in order of polarity. Cardiotoxicity was produced by cumulative administration of Dox $(2.5 \mathrm{mg} / \mathrm{kg}$, i.p. alternative day for two weeks). All four fractions (PEBD-20 mg/kg, CLBD-25 mg/kg, EABD-30 mg/kg and AQBD-25 mg/ $/ \mathrm{kg}$ ) and vitamin E as standard $(100 \mathrm{mg} / \mathrm{kg})$ were administered orally as pretreatment for two weeks followed by Dox on alternative days for two weeks. The general observations, biomarker enzymes like lactate dehydrogenase (LDH), Creatine kinase (CK-MB) and Troponin-I (cTnl), biochemical parameters such as aspartate aminotransferase (AST) and alanine aminotransferase (ALT) were monitored after three weeks of last dose. Myocardial toxicity was also evaluated by histopathologic studies. Results: Repeated administration of Dox-induced cardiomyopathy characterized with an increased
\end{abstract}

level of biomarkers and antioxidant deficit. Pretreatment with the EABD and Vit-E significantly protected myocardium from the toxic effects of Dox by reducing the elevated level of biomarker enzymes like LDH, CK-MB, biochemical parameters such as AST and ALT, absence of cTnl and restoring of disorganized myocardial tissue to normal. Conclusion: The biomarker, biochemical and histopathological data evidently substantiate the cardioprotective effect of EABD, which could be attributed to flavanoids present in the ethyl acetate fraction.

Key words: Boerhaavia diffusa, Cardiotoxicity, Doxorubicin, Troponin-I, CKMB.

Correspondence :

Dr. B.C.Koti, Professor \& Head, Department of Pharmacology, KLE University's College of Pharmacy, Vidyanagar, Hubballi-580 031, Karnataka, India.

Phone: +91 836-2373174

Fax: +91 836-2371694

Email: nimbal_skn@yahoo.co.in; bc_koti@yahoo.com

DOI: 10.5530/jyp.2017.9.104

\section{INTRODUCTION}

Anrthacycline class of drugs (mainly doxorubicin) is one of the most effective anti-cancer agent used to treat various tumours such as solid tumors, leukemia, soft tissue sarcoma, breast cancer, small cell carcinoma of the lung and esophageal carcinomas. ${ }^{1}$ Proposed mechanisms by which doxorubicin acts include intercalation into DNA, DNA cross linking, induction of apoptosis by inhibition of topoisomerase -II, interference with DNA unwinding and direct membrane damage. ${ }^{2,3}$ Its use has been restricted due to its dose dependent cardiotoxicity, which leads to myocardial damage, resulting in cardiomyopathy with fatal congestive cardiac failure. Mechanisms for this cardiotoxicity are not completely understood. The possible proposed mechanisms are free radical generation, lipid peroxidation, mitochondria damage, decreased activity of $\mathrm{Na}^{+}-\mathrm{K}^{+}$ adenosine triphosphate, vasoactive amine release and cellular toxicity. ${ }^{4-7}$ Several hypotheses have been postulated for the development of oxygen free radicals in the development of cardiomyopathy due to presence of semiquinone in the tetracycline aglycone molecule of doxorubicin and it is reported to increase the generation of superoxide radicals that damage the heart by exceeding detoxifying agents of cardiac mitochondrial tissues and sarcoplasmic reticulum. ${ }^{8}$ There are various strategies by which, doxorubicin induced cardiotoxicity can be reduced which includes reducing the total cumulative dose, co-therapy with protective agents, changing the chemical structure, encapsulation in liposomes and development of safe new derivatives. ${ }^{9,10}$ It has been observed that, there is a growing interest in the use of natural antioxidants as a protective strategy against doxorubicin induced cardiotoxicity.
Boerhaavia diffusa Linn belongs to family Nyctaginaceae has been traditionally used in culinary practices and distributed all over India. Traditionally in Ayurveda it has been used for the cardiac disorders. ${ }^{11,12}$ It has been reported to have analgesic and anti-inflammatory, ${ }^{13}$ antistress, ${ }^{14}$ antioxidant, ${ }^{15}$ hepatoprotective, ${ }^{16}$ anticonvulsant ${ }^{17}$ and diuretic. ${ }^{18}$ Earlier we reported that ethanolic extract of whole plant of Boerhaavia diffusa had protected cardiotoxicity induced by doxorubicin. ${ }^{19}$ Further studies were carried out for fractions of ethanolic extract whole plant of Boerhaavia diffusa to know the constituents responsible for cardioprotective activity.

\section{MATERIALS AND METHODS}

\section{Plant material}

The whole plant of Boerhaavia diffusa was procured and authenticated by Dr. Madhav Chetty, Department of Botony, Sri Venkateshwar University, Tirupati, India. Shade dried plant was subjected to size reduction to obtain uniform coarse powder of 40 mesh sizes and powder of the plant was subjected to organoleptic evaluation like colour, taste and odour.

\section{Preparation of the ethanolic extract and fractions}

The ethanolic extract was prepared by macerating whole plant of Boerhaavia diffusa in ethanol for $1 \mathrm{~h}$. Further hot extraction was carried out by refluxing for $1 \mathrm{~h}$, after $1 \mathrm{~h}$ cooled and concentrated using rotary flash evaporator and dried undervaccum. ${ }^{20}$

This is an open access article distributed under the terms of the Creative Commons Attribution-NonCommercial-ShareAlike 4.0 License, which allows others to remix, tweak, and build upon the work non-commercially, as long as the author is credited and the new creations are licensed under the identical terms. 
The dried ethanolic extract of Boerhaavia diffusa was fractionated using petroleum ether, chloroform, ethyl acetate and aqueous in increasing order of their polarity. Each fraction was concentrated by using rotary evaporator and kept in desiccator to completely remove moisture.

\section{Chemicals and drugs}

Doxorubicin was obtained as sample gift from Get Well Pharmaceuticals, India. All chemicals, solvents and enzyme assay kits were purchased of analytical grade.

\section{Animals}

Healthy albino Wistar rats were procured from Venkateswara enterprises, Bangalore and rats weighing between 150-200 g were used for the study after securing the ethical clearance from Institutional Animal Ethical Committee (Ref. No. KLEU's-08-IAEC.HBL-31/Aug2013). All the rats were housed in a polyethylene cages, group of six under environmentally controlled room with $12 \mathrm{~h}$ light/dark cycle and they were fed with standard rat feed and water ad libitum was provided. Rats were acclimatized for one week to laboratory conditions before starting the experiment.

\section{Preliminary phytochemical screening}

Preliminary phytochemical screening was carried out for all fractions to confirm the presence of phytoconstituents. ${ }^{21,22}$

\section{Experimental design}

After one week of acclimatization, the animals were randomly divided into 7 groups of 6 animals in each as follows.

Group I served as normal control, received vehicle $5 \mathrm{ml} / \mathrm{kg}$ body weight orally for two weeks followed by saline i.p. for two weeks.

Group II animals received vehicle $5 \mathrm{ml} / \mathrm{kg}$ body weight orally for two weeks followed by doxorubicin $2.5 \mathrm{mg} / \mathrm{kg}$ body weight i.p. in six equal injections alternative day for two weeks.

Group III animals received Petroleum ether fraction of Boerhaavia diffusa (PEBD-20 mg/kg body weight p.o.) for two weeks followed by doxorubicin as in group II.

Group IV animals received Chloroform fraction of Boerhaavia diffusa (CLBD-25 mg/kg body weight p.o.) for two weeks followed by doxorubicin as in group II.

Group V animals received Ethyl acetate fraction of Boerhaavia diffusa (EABD-30 mg/kg body weight p.o.) for two weeks followed by doxorubicin as in group II.

Group VI animals received Aqueous fraction of Boerhaavia diffusa (AQBD-25 mg/kg body weight p.o.) for two weeks followed by doxorubicin as in group II.

Group VII animals received Standard drug Vit-E $(100 \mathrm{mg} / \mathrm{kg}$ body weight p.o.) for two weeks followed by doxorubicin as in group II.

\section{Food and water}

Food consumption and water intake were regularly measured for throughout study period for all the animals.

\section{Enzyme assays}

Thirty six hour after the last treatment, blood was withdrawn by retroorbital plexus under light ether anesthesia using heparinized microcapillaries for the estimation of various biomarkers like lactate dehydrogenase $(\mathrm{LDH}){ }^{23}$ creatinine phosphokinase $(\mathrm{CPK})^{24}$ and troponin-I $(\mathrm{cTnI}){ }^{25}$ After these experiments, all the animals were observed for next three weeks for the general appearance, behavior and mortality. After the three weeks, again blood was withdrawn by retro-orbital plexus under light ether anesthesia using heparinized microcapillaries for the estimation of aspartate transaminase (AST) ${ }^{26}$ and alanine transaminase (ALT) ${ }^{26}$ Animals were sacrificed under ether anesthesia and a midline incision was performed and heart tissue was quickly dissected out, washed in ice cold saline, dried by filter paper.

\section{Histopathological studies}

The heart tissue sections were fixed in $10 \%$ formalin, the specimens were processed by standard procedure and embedded in paraffin wax. The blocks were sectioned from the ventricular portion and stained according to the hematoxylin and eosin method and were examined by microscopy. ${ }^{27}$

\section{Statistical analysis}

The experimental data were statistically analyzed using one-way analysis of variance (ANOVA) followed by Dunnett's multiple comparison test using Graphpad Prism 5.0. Data were expressed as Mean \pm S.E.M. and $p<0.05$ was considered as significant.

\section{RESULTS}

\section{Phytochemical investigation}

Preliminary phytochemical studies exhibited the presence of steroids and fatty acids in PEBD; alkaloids in CLBD; flavonoids, triterpenoids and tannins in EABD; and carbohydrates in AQBD.

\section{General observations}

Doxorubicin administered rats had a scruffy hair and red exudates around the eyes and soft watery faeces along with necrosis at the site of administration. These conditions were severe during the last six days of study period. But these changes were significantly less in pretreated EABD fraction and Std treated group rats. Figure 1 depicts that significant reduction of body weight in doxorubicin $(p<0.001)$ administered rats as compared to control group rats. It is due to reduced water and food consumption as shown in Table 1. However, among the treatment with different fractions, only EABD $(\mathrm{p}<0.5)$ and Std treated rats had significantly improved body weight $(\mathrm{p}<.0 .5)$ as well as water and food consumption $(\mathrm{p}<0.001$ and $\mathrm{p}<0.01)$ respectively as compared to doxorubicin group.

\section{Cardiac markers}

The doxorubicin treated rats showed significant increase in $\mathrm{LDH}$ $(\mathrm{p}<0.001)$ and CK-MB $(\mathrm{p}<0.001)$ and also the presence of cardiac Troponin I as compared to control group (Table 2). The pretreatment groups EABD and standard treated rats had significantly decreased the levels of LDH $(\mathrm{p}<0.5$ and $\mathrm{p}<0.01)$ and CK-MB $(\mathrm{p}<0.01$ and $\mathrm{p}<0.01)$

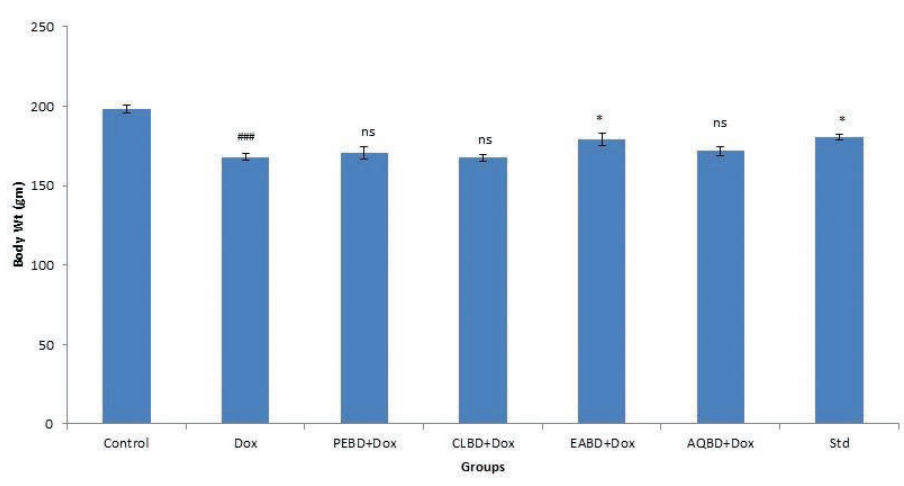

Figure 1: Effect of EEBD fractions on body weight 
Table 1: Effect of EEBD fractions on water and food consumption

\begin{tabular}{ccc}
\hline Groups & Water $(\mathrm{mL} /$ day/rat $)$ & Food $(\mathrm{g} /$ day/rat $)$ \\
\hline Control & $25.83 \pm 0.4469$ & $24.07 \pm 0.4332$ \\
Dox & $15.72 \pm 1.753^{* \# \#}$ & $14.79 \pm 1.633^{\# \# *}$ \\
PEBD + Dox & $17.72 \pm 1.604$ & $14.89 \pm 1.496$ \\
CLBD + Dox & $18.52 \pm 1.485$ & $16.00 \pm 1.467$ \\
EABD + Dox & $20.97 \pm 1.222^{*}$ & $20.21 \pm 0.8779^{*}$ \\
AQBD + Dox & $18.59 \pm 1.368$ & $14.82 \pm 1.372$ \\
Std + Dox & $22.86 \pm 0.7489^{* * *}$ & $20.61 \pm 1.007^{* *}$ \\
\hline
\end{tabular}

The experimental data were statistically analyzed using one-way analysis of variance (ANOVA) followed by Dunnett's multiple comparision test and expressed as Mean \pm S.E.M. $(. n=6) ; * * \mathrm{p}<0.001$ when compared to control group, $\cdots \mathrm{p}<0.001$ and $\cdot \mathrm{p}<0.05$ when compared to Dox.

Dox- Doxorubicin, PEBD-Petroleum ether fraction, CLBD-Chloroform fraction, EABD-Ethyl acetate fraction, AQBD-Aqueous fraction, Std-Standard treated with Vitamin-E.

Table 2: Effect of EEBD fractions on cardiac markers

\begin{tabular}{cccc}
\hline Groups & LDH (IU) & CK-MB (IU) & $\begin{array}{c}\text { Cardiac troponin I } \\
\text { (cTnl) }\end{array}$ \\
\hline Control & $106.7 \pm 15.84$ & $65.67 \pm 9.062$ & - \\
Dox & $191.5 \pm 11.25^{* * * *}$ & $159.5 \pm 10.72^{* \# *}$ & + \\
PEBD + Dox & $185.5 \pm 16.50$ & $153.2 \pm 13.76$ & + \\
CLBD + Dox & $179.0 \pm 10.41$ & $155.2 \pm 10.88$ & + \\
EABD + Dox & $140.3 \pm 10.17^{*}$ & $99.50 \pm 7.697^{* *}$ & - \\
AQBD + Dox & $173.3 \pm 9.691$ & $154.5 \pm 15.09$ & + \\
Std + Dox & $126.8 \pm 12.86^{* *}$ & $91.17 \pm 15.27^{* *}$ & - \\
\hline
\end{tabular}

The experimental data were statistically analyzed using one-way analysis of variance (ANOVA) followed by Dunnett's multiple comparision test and expressed as Mean \pm S.E.M. $(. n=6) ; * * \mathrm{p}<0.001$ when compared to control group; ${ }^{* *} \mathrm{p}<0.01$ and $\cdot \mathrm{p}<0.05$ when compared to Dox.

Dox- Doxorubicin, PEBD- Petroleum ether fraction, CLBD-Chloroform fraction, EABD-Ethyl acetate fraction, AQBD-Aqueous fraction, Std-Standard treated with Vitamin-E.

'+' Present, '-' Absent

Table 3: Effect of EEBD fractions on serum markers

\begin{tabular}{ccc}
\hline Groups & AST (IU) & ALT (IU) \\
\hline Control & $40.17 \pm 6.745$ & $29.67 \pm 5.445$ \\
Dox & $121.7 \pm 19.13^{\# \# \#}$ & $115.7 \pm 22.21^{\# \#}$ \\
PEBD + Dox & $117.7 \pm 14.46$ & $91.67 \pm 17.25$ \\
CLBD + Dox & $120.5 \pm 12.36$ & $96.17 \pm 15.27$ \\
EABD + Dox & $71.00 \pm 12.65^{*}$ & $58.50 \pm 9.006^{*}$ \\
AQBD + Dox & $115.8 \pm 12.42$ & $88.50 \pm 15.07$ \\
Std + Dox & $58.67 \pm 10.46^{* *}$ & $40.17 \pm 8.089^{* *}$ \\
\hline
\end{tabular}

The experimental data were statistically analyzed using one-way analysis of variance (ANOVA) followed by Dunnett's multiple comparision test and expressed as Mean \pm S.E.M. $(. n=6) ; * * \mathrm{p}<0.001$ when compared to control group; ${ }^{* *} \mathrm{p}<0.01$ and ' $\mathrm{p}<0.05$ when compared to Dox.

Dox- Doxorubicin, PEBD-Petroleum ether fraction, CLBD-Chloroform fraction, $E A B D$-Ethyl acetate fraction, AQBD-Aqueous fraction, Std-Standard treated with Vitamin-E.
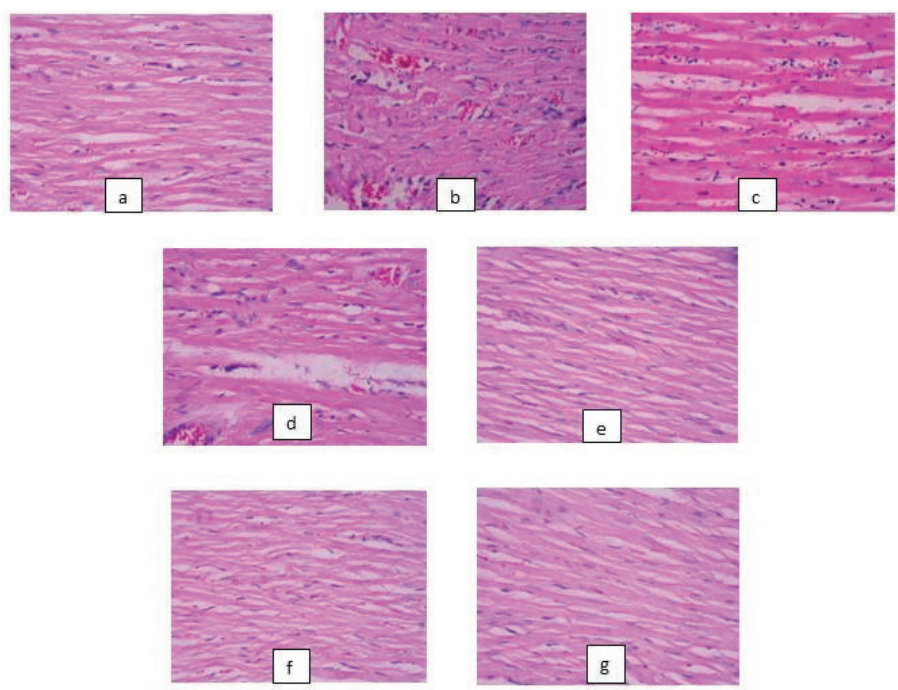

Figure 2: Histopathological study of cardiac muscle tissue (a) Photomicrograph of normal group heart showing normal myocardial fibers and architecture. (b)Doxorubicin treated group showing loss of myocardial fibers and vacuolated cells.(c), (d) and (f) Pretreated with PEBD, CLBD and AQBD respectively showing loss of myocardial fibers and vacuolated cells.(e) and (g) EABD+Dox and Std+Dox group respectively showing scanty myocardial fibers loss and vacuolated cells.

respectively and also the absence of cardiac Troponin I as compared with doxorubicin group.

\section{Serum markers}

Table 3 presents doxorubicin treated rats, produced significant increase in serum enzyme markers AST $(\mathrm{p}<0.001)$ and ALT $(\mathrm{p}<0.01)$ as compared to control group but pretreated groups i.e. EABD and standard treated had significantly decreased the levels of AST $(\mathrm{p}<0.5$ and $\mathrm{p}<0.01)$ and ALT $(\mathrm{p}<0.5$ and $\mathrm{p}<0.01)$ respectively as compared to doxorubicin group.

\section{Histopathological studies}

Figure 2 showed heart tissue of doxorubicin treated rats exhibited loss of myofibrils, vacuolization of the cytoplasm and inflammatory cells compared to control rats which showed normal morphological appearances. In EABD and standard pretreated rats there was minimal loss of myofibrils and vacuolization of cytoplasm as compared to doxorubicin treated group.

\section{DISCUSSION}

The Anthracycline derivative doxorubicin is one of the most cytotoxic antibiotic and useful in numerous chemotherapy regimens to treat haematological and other solid tumours. The mechanism for antineoplastic is by intercalation of DNA, preventing replication and protein synthesis, and inhibition of topoisomerase-II, preventing topoisomerase-IIdependent relegation after double-strand breakage. Although it is an effective anticancer drug, but dose dependent cardiotoxicity, which is characterized by acute or early/late onset chronic progressive cardiomyopathy is a common side effect of doxorubicin therapy and because of this its therapeutic use restricted or limited..$^{28}$

Mitochondrial reductase reduces the doxorubicin by one electron and may generate anthracycline semiquinone free radicals ${ }^{29}$ and under aerobic conditions these are unstable and readily reduce molecular oxygen to the reactive oxygen species superoxide anion and hydrogen peroxide. ${ }^{30}$ 
Increased free radical generation in cardiomyocytes produces oxidative stress that may lead to multiple adverse effects. ${ }^{28}$

In present study we investigated the influence of four fractions (Petroleum ether, Chloroform, Ethyl acetate and Aqueous) of ethanolic extract of Boerhaavia diffusa against doxorubicin induced myocardial toxicity. Doxorubicin treated rats showed scruffy fur, alopecia and on later days red exudates around the eyes, nose and also necrosis at the site of injection. These changes were reduced in ethyl acetate fraction of EEBD and standard (Vit-E) treated group rats. There was reduction in body weight due to reduction in water and food consumption in doxorubicin treated rats. However these changes were prevented by ethyl acetate fraction and Std (Vit-E) pretreated rats.

This study also showed the oxidative damage due to increase in ROS in the cardiac tissue after administration of doxorubicin. Damage of cardiac tissue results into release of certain cardiac markers like LDH, CK-MB and cTn-I into the blood stream and these served as diagnostic markers of cardiac damage. The amount of these markers present in the blood reflects the alteration in plasma integrity and/or permeability.

After doxorubicin administration these cardiac markers levels were significantly elevated which is an indicator of the myocardial damage which is in agreement with our earlier reports ${ }^{19}$. In pretreated groups only ethyl acetate fraction and Vit-E group significantly reduced the doxorubicin induced elevated cardiac markers. Hence this evidently confirms that the phytoconstituents mainly flavanoids present in the fractions are responsible for maintenance of normal structural and cardiac tissue architectural integrity thereby inhibiting the leakage of these markers into the blood stream which can be accounted for its membrane stabilizing property.

Histopathological reports showed doxorubicin administered rats had enlarged heart, swollen mitochondria and presence of vacuoles within cytoplasm. There was degeneration of myocardial tissue, myofibrillar loss, myocardial hypertrophy and fragmentation of nuclei because of vacuolar changes in cardiac muscle fibers. These changes are due doxorubicin has high affinity for the mitochondrial phospholipid cardiolipin, which is localized to the inner mitochondrial membrane and important to mitochondrial structure, function and metabolism in cardiomyocytes. Accumulation of doxorubicin in mitochondria via interaction with cardiolipin may produce a significant increase in reactive oxygen species in cardiac tissue. ${ }^{31}$ The ethyl acetate fraction contains flavanoids, which might reduce the formation of reactive oxygen species, thus decreasing the oxidative stress and producing cardioprotective activity. It has been reported that the bioflavanoids have a protective effect on the DNA damage induced by the free radicals. ${ }^{32,33}$

\section{CONCLUSION}

The doxorubicin induced cardiotoxicity is mainly due to its oxidative stress. Ethyl acetate fraction of EEBD mainly containing flavonoids, which are responsible for its anti-oxidant property. Our study revealed that ethyl acetate fraction containing high amount of flavanoids may be considered as potentially useful in combination with doxorubicin to reduce/limit free radical mediated cardiac injury. However, further studies are certainly required to isolate and characterize flavonoid phytoconstituents of ethyl acetate fraction responsible for cardio protective property.

\section{ACKNOWLEDGMENT}

The authors are thankful to the Principal and Staff members of KLEU's College of Pharmacy, Vidyanagar, Hubballi, for providing all necessary facilities and help to carry out the research work.

\section{CONFLICT OF INTEREST}

No conflict of interest.

\section{ABBREVIATION USED}

PEBD: Petroleum ether fraction of Boerhaavia diffusa; CLBD: Chloroform fraction of Boerhaavia diffusa; EABD: Ethyl acetate fraction of Boerhaavia diffusa; AQBD: Aqueous fraction of Boerhaavia diffusa; Dox: Doxorubicin; LDH: Lactate dehydrogenase; CK-MB: Creatinine Kinase MB; cTnI: Cardiac troponin I; AST: Asparatate transaminase; ALT: Alanine transaminase.

\section{REFERENCES}

1. Blum RH, and Carter SK. Adriamycin. A new anticancer drug with significant clinical activity. Ann Intern Medicine. 1974;80(2):249-59.

2. Gewirtz DA. A critical evaluation of the mechanisms of action proposed for the antitumor effects of the anthracycline antibiotics Adriamycin and daunorubicin. Biochem Pharmacol. 1999;57(7):727-41.

3. Minotti G, Menna P, Salvatorelli E, Cairo G and Gianni L. Anthracyclines: molecular advances and pharmacologic developments in antitumor activity and Cardiotoxicity. Pharmacol Rev. 2004;56(2):185-229.

4. Doroshow JH. Effect of anthracycline antibiotics on oxygen radical formation in rat heart. Cancer Res. 1983;43(2):460-72.

5. Bristow MR, Sageman WS, Scott RH, Billingham ME, Bowden RE, Kernoff RS et al. Acute and chronic cardiovascular effects of doxorubicin in the dog: the cardiovascular pharmacology of drug-induced histamine release. J Cardiovasc Pharmacol. 1980;2(5):487-515.

6. Mettler FP, Young DM and Ward JM. Adriamycin-induced Cardiotoxicity (Cardiomyopathy and Congestive heart failure) in Rats. Cancer Res. 1977; 37(8 Part 1) :2705-13.

7. Tong J, Ganguly PK and Singal PK. Myocardial adrenergic changes at two stages of heart failure due to Adriamycin treatment in rats. Am J Physiol Heart Circ Physiol. 1991;260(3):H909-16.

8. Kaithiwas G, Dubey K and Pilliai K. Effect of Aloe vera (Aloe berbadensis Miller) gel on doxorubicin induced myocardial oxidative stress and calcium overload in albino rats. Ind J Exp Biol. 2011;49:260-68.

9. Jung K and Reszka R. Mitochondria as subcellular targets for clinically usefu Anthracyclines. Adv Drug Deliv Rev. 2001;49(1):87-105.

10. Singal PK, lliskovic $N$ and Kumar D. Adriamycin cardiomyopathy: pathophysiology and prevention. Faseb J. 1997:11(12):931-6.

11. Kirtikar KR. Basu BD. Indian Medicinal Plants. Periodical Experts Book Agency, Delhi.1991.

12. The Wealth of India. Raw Materials Vol 2B \& IX. Publicatiion and Information Directorate. CSIR. New-Delhi. 2003

13. Hiruma CA, Gracioso JS, Bighetti EJ, Germonsen RL, Souza B. The juice of fresh leaves of Boerhaavia diffusa L. (Nyctaginaceae) markedly reduces pain in mice. J Ethnopharmacol, 2000;71(1-2):267-74

14. Meera S, Mustafa SS. Anti-stress, Adaptogenic and Immunopotentiating activity of Roots of Boerhaavia diffusa in mice. Int J Pharmacology, 2007;3(5):416-20.

15. Tolulope OM, Afolabi C, Adebayo A. Antioxidant and Hepatoprotective property of leaf extracts of Boerhaavia diffusa Linn against acetaminophen induced Liver damage in rats. Food Chem Toxicol. 2010;48:2200-5

16. Chandan BK, Sharma AK, Anand KK. Boerhaavia diffusa: A study of its hepatoprotective activity. J Ethanopharmacol. 1991;31(3):299-07.

17. Mandeep K, Rajesh G. Anti-convulsant activity of Boerhaavia diffusa: Plausible role of Calcium Channel Antagonism. Evidence-based Complementary and Alternative Medicine. 2011; article ID 310420.

18. Parasuraman $\mathrm{S}$, Kumar $\mathrm{E}$, Kumar $\mathrm{A}$, Emerson $\mathrm{S}$. Free radical scavenging property and diuretic effect of triglize, a polyherbal formulation in experimental models. J Pharmacol Pharmacother. 2010;1(1):38-41.

19. Nimbal SK, Koti BC. Cardioprotective effect of Boerhaavia diffusa against Doxorubicin-induced myocardial toxicity in albino rats. Sch. Acad. J. Biosci. 2016;4(2):171-8

20. World Health Organization. Geneva. Quality Control Methods for medicinal plant materials.1998;s30.

21. Kokate CK. Practical Pharmacognos, $4^{\text {th }}$ ed. New Delhi, Vallabh Prakashan. 1994

22. Harborne JB. Phytochemical Methods, $3^{\text {rd }}$ ed. Chapman and Hall, London. A guide to modern techniques of plant analysis. 2007;16-32.

23. Henry RJ, Chiamori N, Goiub OJ and Berkman S. Revised spectrophotometric methods for the determination of glutamicoxalacetic transaminase, glutamicpyruvic transaminase and lactic acid dehydrogenase. Am J Clin Pathol. 1960; 34:381-98.

24. Bremmer FW. Cardiac disease and hypertension in "Clinical Chemistry theory, analysis and correlation." Kaplan L and Pesce A (eds) CV Mosby company. 1987. 
25. Adams. Biochemical markers of myocardial injury. Immunoassay Circulation. 1993;88(2):750-63.

26. Reitman $\mathrm{S}$ and Frankel AS. A colorimetric method for the determination of serum glutamyl oxalacetic acid glutamyl pyruvate transaminase. Am J Clin Pathol. 1957;28(1):56-63

27. Agadihiremath VS, Sumeet G, Agadihiremath T, Basavaraj CK and Donnahalli VM. Cardioprotective effect of curcumin against doxorubicin-induced myocardial toxicity in albino rats. Indian J Pharmacol. 2012;44(1):73-7.

28. Damian GD, Elizabeth AM, Judith $M H$ and Ruth R. Drug-Induced Oxidative Stress and Toxicity. J Toxicol. 2012;1-13.

29. Davies KJ and Doroshow JH. "Redox cycling of anthracyclinesby cardiac mitochondria. I. Anthracycline radical formation by NADH dehydrogenase". J.
Biol Chem. 1986;261(7):3060-7.

30. Doroshow JH and Davies KJ. "Redox cycling ofanthracyclines by cardiac mitochondria. II. Formation ofsuperoxide anion, hydrogen peroxide, and hydroxyl radical". The Journal of Biological Chemistry. 1986;261(7):3068-74.

31. Goormaghtigh E, Chatelain P, Caspers J and Ruysschaert JM. "Evidence of a specific complex between Adriamycin and negatively-charged phospholipids". Biochimicaet Biophysica Acta. 1980; 597(1):1-14.

32. Russo A, Acquaviva R, Campisi A, Sorrenti V, Giacomo CD and Virgata V, et al Bioflavonoids as antiradicals, antioxidants and DNA cleavage protectors. Cell Biol. Toxicol. 2000;16:91-8.

33. Pietta PG. Flavonoids as antioxidants. J Nat Prod. 2000;63(7):1035-42.

Article History: Submission Date : 23-06-2017 ; Revised Date : 31-07-2017; Acceptance Date : 19-08-2017.

Cite this article: Nimbal SK, Koti BC. Effect of Ethanolic Extract Fractions of Boerhaavia diffusa in Doxorubicin-induced Myocardial Toxicity in Albino Rats. J Young Pharm. 2017;9(4):545-9. 